INVESTIGACIÓN/RESEARCH

\title{
EL CASO DE LA RED SOCIAL PINTEREST: REPRESENTACIÓN PROPIA Y COLECCIONISMO VIRTUAL A TRAVÉS DE IMÁGENES
}

Mariona Visa Barbosa ${ }^{1}$ : Universitat de Lleida. España.

marionavisa@filcat.udl.cat

\section{RESUMEN}

Los usos de la fotografía nos hablan de la sociedad de cada momento y en los últimos años vemos como la representación personal, la comunicación y el coleccionismo forman parte de estos usos. Muchos usuarios de las redes sociales no producen contenido, sino que lo utilizan como herramienta para comunicarse entre ellos. La plataforma emergente Pinterest es un lugar dónde organizar aquello que nos interesa en distintas carpetas y a la vez exhibirlo al resto del mundo, posibilitando así la transmisión de información y la comunicación horizontal entre los usuarios, característica clave de los medios sociales que pueblan Internet desde principios del siglo XXI.

PALABRAS CLAVE: Etiqueta - Internet - Comunicación Digital - Individualidad Imagen.

\footnotetext{
${ }^{1}$ Autora correspondiente:

Mariona Visa Barbosa: Profesora investigadora en la Universitat de Lleida, en el Grado de Periodismo y Comunicación Audiovisual. España.

Correo: marionavisa@filcat.udl.cat
} 


\title{
THE CASE OF PINTEREST: SELF REPRESENTATION AND VIRTUAL COLLECTION THROUGH IMAGES
}

\begin{abstract}
If the uses of photography illustrate the society of each moment, in our current hypermodern era we see how the personal representation, the communication and the collecionism are part of these uses. Many users of social networks do not produce content for themselves, but use it instead as a tool to communicate between them. The platform Pinterest is a place to organize the things in which we are interested in in different folders at the same time that we can show them to the rest of the world. Thus enables the transmission of information and the horizontal communication between users, key features of the social media in Internet.
\end{abstract}

KEYWORDS: Tag - Internet - Digital Communication - Individuality - Image.

\section{INTRODUCCIÓN}

Los primeros años de popularización de Internet, en la década de los 90 del siglo XX, el uso principal que se hacía de este nuevo medio era la transmisión de información, de manera vertical, de las instituciones a los usuarios. Era la conocida web 1.0, a la que posteriormente se le fueron añadiendo nuevos usos, sin dejar éste de ser vigente en la actualidad.

A finales de los 90 del siglo pasado, los usuarios fueron usando paulatinamente Internet para comunicarse entre sí y para transmitirse información de manera horizontal. Así, cada vez más personas anónimas, que no representaban instituciones ni empresas tuvieron su sitio en la red. Algunos usuarios empezaron a tener pequeñas páginas a modo de bitácoras dónde exponían sus experiencias personales o profesionales.

Blogger, la página que permite crear una bitácora personal en línea sin necesidad de que el usuario tenga que conocer los códigos informáticos básicos para hacerlo, fue oficialmente creada en 1999, y la expansión de este tipo de páginas fue en aumento a medida que aumentaba la velocidad de subida y de descarga de datos. Estaba llegando la conocida cómo web 2.0 (OReilly Media, 1999), que se instauró definitivamente con la creación de Facebook en 2004. La posibilidad de compartir pensamientos, fotografías y datos de manera fácil y sencilla entre usuarios de distintos países revolucionó el uso que se hacía de Internet.

En 2006, el lanzamiento de Twitter vino a conformar todavía más esta red social. Y luego vinieron más, cómo Flikr o la emergente Pinterest que nos ocupa, todas ellas páginas que facilitan la transmisión de información y la comunicación horizontal entre los usuarios. 
Así, en la época actual dónde se debate sobre la web semántica o web 3.0 (Codina, 2009), que es la que permite intercambiar datos y procesarlos para generar nueva información; las iniciativas colaborativas que definieron la web 2.0 aún se instalan con fuerza y consiguen millones de usuarios.

Hablaremos aquí de la plataforma Pinterest, creada en Estados Unidos en diciembre de 2009. Pinterest forma parte de éstas plataformas de colaboración, siendo un lugar dónde el usuario puede organizar aquello que le interesa en distintas carpetas y a la vez exhibirlo al resto del mundo. Pinterest sirve para compartir fotografías, al estilo de los antiguos muros o murales de pared. También sirve para conectar y conocer gente con los mismos intereses, a las que les gustan las mismas cosas. Así, los usuarios van organizando aquello que encuentran, tanto dentro de su propio ordenador como en Internet, en distintas carpetas. Es la versión actual de mirar catálogos o revistas especializadas en nuestros gustos. En esta plataforma, el usuario puede crear su propia revista y a la vez compartirla con familiares, amigos o desconocidos, que a la vez, pueden hacer un re-pin (distribuir de nuevo) y organizar en sus propias carpetas aquello nuestro que les gusta.

En enero de 2012, la página tenía $11^{\prime} 7$ millones de usuarios (según comScore). La mayoría de los usuarios actuales son mujeres, en un $80 \%$, y un $50 \%$ son usuarios con niños a su cargo (según publicó The Huffington Post en un artículo a finales del año 2012). A continuación analizaremos cuáles son sus características básicas para establecer sus principales funciones.

\section{METODOLOGÍA}

Este artículo se propone ver qué tipo de fotografías abundan entre los usuarios de la red social Pinterest, qué usos tienen éstas, y compararlas con otros usos de las imágenes en otras redes sociales y en entornos comunicativos a distancia. Se analizará el porqué del éxito de la comunicación a través de imágenes, a partir de repasar la presencia de éstas y su uso comunicativo en otras redes sociales como Facebook o Photoblog. Para ello, se partirá de los resultados establecidos en trabajos anteriores de la autora, como La re-creación de la identidad a través de la fotografía en las imágenes de perfil de la red social Facebook (Visa, 2011) y El uso del photoblog como narración, juego y construcción de la propia identidad (Visa, Merola, 2012), para comparar usos y funciones de las imágenes entre estas plataformas.

Otros aspectos que conforman la base de este estudio son el análisis del coleccionismo virtual que se hace a partir de imágenes, la exhibición propia a través de éstas y la organización de intereses personales de manera pública, y el uso de la plataforma Pinterest como punto de encuentro para conocer a personas con intereses semejantes.

Así pues se analizara la red social desde el punto de vista sociológico descrito por Erving Gofmann cuando hablaba de las interacciones entre personas, ya que se quiere ver si los usuarios adoptan un rol característico en la red y cuáles son las herramientas que utilizan para reforzar su identidad en la vida virtual. No olvidemos que estar en las redes sociales es una manera de hacerse ver, de ser visible socialmente, y que esto 
se consigue en parte gracias a la exhibición de las fotografías propias, con las que nos presentamos a los que ya nos conocen pero también a aquellos que hace tiempo que no vemos y a los amigos de nuestros amigos. A diferencia de otras redes sociales, como Facebook, que son utilizadas mayoritariamente por usuarios que ya se conocen en la vida real y quieren comunicarse también a través de Internet; Pinterest amplía sus horizontes a usuarios que quieren conocer gente nueva que tenga sus mismos intereses,

Por lo que respecta a la organización de los intereses personales, se describe la forma de etiquetaje actualmente presente en esta red, dónde son los propios usuarios quienes clasifican su propia información, siguiendo lo que se ha descrito como la folcsonomía, que como afirmó el investigador de estudios semánticos Peter Morville conduce a la inteligencia colectiva.

Así, la metodología que se sigue para realizar este análisis es multidisciplinar, incluyendo un análisis descriptivo, compositivo, tecnológico, narrativo y sociológico de las imágenes, en función de sus usos.

Y el marco de estudio se inscribe en la era actual hipermoderna, como ha sido definida por sociólogos como Gilles Lipovetsky o Zygmunt Bauman. Pasados los momentos de máxima exaltación alrededor del hedonismo y del presentismo propios de la tardomodernidad, en los últimos años se vive una recomposición de valores, algunos de los cuáles se inscriben todavía en la era de Narciso (como llamaba Lipovetsky a la tardomodernidad), pero dónde algunos se han modificado o han adquirido cierta ambivalencia.

Esta época se inicia durante el último tercio del siglo $X X$, coincidiendo con muchos cambios de la sociedad. La caída del muro de Berlín el año 1989, la crisis ambiental y la revolución informacional, entre otros factores, comportaron una variación de les grandes ideologías. Igualmente, una progresiva "descomunitarización" de los marcos que hasta entonces eran vividos como comunitarios; debido sobre todo a la complejidad social, el sensualismo, la desacralización del mundo, el racionalismo moderno y la secularización propios de la sociedad en esta última etapa del modernismo (y que han sido apuntados por Joaquim Capdevila (Capdevila, 2011: 28), desemboca en una necesidad de afirmación de la identidad personalizada de los individuos.

El "carpe diem" propio de las décadas pasadas se concilia con una preocupación por el futuro, que ha vuelto de nuevo y no con los mejores pronósticos. Cada vez hay más sensaciones de incertidumbre y de inseguridad asociadas al futuro más o menos inmediato. Un pesimismo difuso parece haberse instalado entre nosotros ye han entrado en franca crisis la fascinación, el progreso y la libertad; los grandes pilares de la primera modernidad, las bases de su imaginario. También, en el marco de estas últimas décadas, el hombre y la mujer occidentales han desarrolladlo unas preocupaciones por el trabajo, la salud y la familia a las cuáles Lipovetsky se ha 
referido bautizando el hombre actual como un "Narciso neurotizado". ( Lipovetsky, 2007).

Zygmunt Bauman define este período como el de una gran ambivalencia. Queremos conseguir las cosas, pero a la vez nos asusta tenerlas. "No hay manera de gozar del lado bueno sin excluir al malo. Las promesas y las amenazas vienen en el mismo paquete. No pueden estar separadas". (Bauman, 2005: 12). Y señala como uno de los ámbitos de más ambivalencia el de las relaciones humanas, en la interacción con otros individuos.

\section{ANÁLISIS Y DESARROLLO}

\subsection{La comunicación a través de imágenes}

Una de las cosas que más llama la atención de Pinterest es que todo aquello que nos interesa se puede representar a través de imágenes. Cada carpeta (board) de los usuarios incluye una serie de fotografías sobre un tema determinado, las cuáles remiten posteriormente a un texto o página web. Se trata, pues, de compartir experiencias y gustos en formato imagen.

Este dato pone de manifiesto que la fotografía, tanto la analógica nacida hace casi dos siglos como la actual fotografía digital, junto con las ilustraciones e imágenes virtuales generadas por ordenador ocupan actualmente un lugar de honor en la comunicación por Internet. Ya en los juegos olímpicos de Atlanta 96, que fue el primer gran evento cubierto por Internet, se vio el triunfo de las imágenes. En una encuesta que la sección de la web de cobertura hizo a los usuarios, éstos señalaron que aquello que más les interesaba de la web- por encima de los videos y informaciones narrativas- era la sección llamada Álbum fotográfico, una galería fotográfica del evento hecha por AFP y All Sport. (Domingo, 1996:69).

Y actualmente, nos comunicamos, más que nunca, con imágenes. El éxito de plataformas como Instagram lo confirman. Facebook combina texto e imagen, pero diversos estudios han confirmado que tienen más popularidad (reciben más me gusta y más comparticiones) las actualizaciones que se acompañan con una imagen, como demuestra el analista social Dan Zarrella en su blog, después de analizar 1'3 millones de actualizaciones. Photoblog permitía escribir algunas líneas debajo de las imágenes publicadas por cada autor (aunque se trataba de un texto muy reducido y con gran cantidad de emoticonos y lenguaje propio del SMS. (Visa, Soto; 2012). Y a parte quedan los casos de Twitter y Blogger, que sí que priorizan la palabra, pero en los que completar la información con imágenes es necesario para atraer visitantes y jerarquizar mejor la información. Flickr y Blogger ya permitían compartir imágenes entre usuarios, pero no al nivel de Pinterest debido sobre todo a que no había todavía móviles con conexión a Internet y esto limitaba la movilidad y rapidez en la divulgación. Además, el concepto de Pinterest es otro: compartir no sólo nuestras imágenes o experiencias, sino también todo aquello con que nos topamos en la red y nos parece interesante. 
Y si nos fijamos en la forma de comunicarnos a través de la aplicación móvil WhatsAp, a través de la cual se pueden enviar imágenes y vídeos muy fácilmente, queda claro que la palabra cada vez es menos indispensable a la hora de comunicar.

El hecho que en Pinterest la hegemonía la tenga también la imagen es muy afín y compatible con los nuevos dispositivos móviles de pantalla pequeña, dónde es más fácil contemplar una imagen que leer un texto, sobre todo si éste es muy largo. Con un solo vistazo captamos aquello que gusta a otras personas, o etiquetamos los que nos gusta a nosotros (en el mismo sentido que las páginas para compartir fotografías como Picplz, Instagram o Lightbox).

Igualmente, en Pinterest el mismo usuario se representa a través de una fotografía y una frase, como es habitual en las redes sociales. Así, la representación del propio yo se hace también a través de una imagen. $Y$ hay que tener en cuenta, que las redes sociales permiten la posibilidad de cambiar a menudo la fotografía del perfil. Hoy en día la gente ya no se limita a definirse a través de un solo retrato. Como dice Berger, "las demandas de la visión moderna son incompatibles con la singularidad del punto de vista'. (Mosquera, 1011: 139). Ya no nos definimos sólo a través del estereotipo de una fotografía de carné, que nos uniformizaba a todos. Ahora tenemos muchas más opciones para representarnos, y a menudo conformamos un yo virtual que se aleja de nuestra identidad real. La investigadora María Gil Posa cree que "construimos nuestra identidad on-line partiendo de rasgos que componen nuestras múltiples identidades off-line; hacemos "ficción" en un contexto de supuesta "realidad" (Gil Posa, 2010) y que, a pesar de las semejanzas con la realidad, estamos creando un personaje. De hecho, la creación de un yo es siempre una arte narrativa, tanto en las redes sociales como en las interacciones cara a cara y siempre representamos un personaje cuando estamos ante un auditorio, por pequeño que sea. Pinterest nos permite hacerlo a través de señalar aquello que nos gusta, no sólo a partir de nosotros mismos.

\subsection{Coleccionar el mundo}

La forma en que organizamos nuestros intereses en Pinterest se asemeja a la visión de un usuario que va recortando la realidad, aunque sin tijeras ni pegamento, y la organiza en su particular mural. Es un claro ejemplo de la necesidad de los individuos de ir adquiriendo pertenencias y de autorepresentarse a través de ellas. El filósofo italiano Gianni Vattimo lo define con el concepto de desrealización y explica como "por una especie de perversión de la lógica interna, el mundo de los objetos mensurables y manipulables por la ciencia técnica (el mundo de lo real, según la metafísica), ha venido a ser el mundo de las mercaderías, de las imágenes, el mundo fantasmagórico de los medios de comunicación." (Vattimo, 2003:16).

Así, todo parece convertido en un objeto de consumo del que podemos disponer, o del que podemos, si más no, apropiarnos (haciendo pin). Si tenemos en cuenta las palabras de Lipovetsky, vemos como "de la era del vacío hemos pasado a la era de la saturación, de la demasía, de lo superlativo en todo". (Lipovetsky, 2007: 73). Y no sólo tenemos que tener esta gran cantidad de imágenes y datos a nuestro alcance, sino que nos sentimos mejor 
si nos las apropiamos. Actualmente los individuos necesitamos expresar singularizadamente más que nunca nuestra identidad. Buscamos unos referentes que nos diferencien fuertemente, que nos singularicen respecto de los demás. Aunque, como contradicción, a la larga nos mimetizan. Los nombres de las carpetas más utilizadas en Pinterest corresponden a gustos universales: música, recetas, juegos, decoración, jardinería, actividades para hacer con niños...

Como los adolescentes que antaño decoraban sus habitaciones con pósteres de sus ídolos, seguimos apropiándonos de imágenes que nos sirven como herramientas para construir y definir nuestra personalidad.

\subsection{Exhibir lo que nos gusta: hacer pública la carpeta de recortes}

Lo que nos gusta nos representa: aquello que comemos, a dónde nos gusta ir, las cosas que coleccionamos, a qué dedicamos el tiempo de ocio, dicen mucho sobre nosotros. Parece así como si, en plena hipermodernidad y con un sentimiento constante de anomia (Capdevila, 2010:16) y desrealización, los individuos necesitáramos más que nunca explicarnos a nosotros mismos y al resto del mundo quiénes somos o quienes queremos ser.

Actualmente, el individuo debe conformarse de nuevo, esta vez sin rebelarse contra lo que no quiere ser, sino empezando de cero. Vivimos actualmente un estado de anomia consecuencia de factores como la perspectiva enormemente panorámica con la que se nos muestra el mundo, la perspectiva de una realidad social extraordinariamente compleja y a la vez imprecisa y la saturación contextual de estímulos, con niveles importantes de entropía y de irrelevancia informativa y de impersonalidad. (Capdevila, 2010:16)

Por este motivo actualmente los individuos necesitan expresar de manera singular su identidad. Y esta personalización extrema de las identidades se beneficia de un fenómeno básico de la hipermodernidad: la emergencia de una nueva dimensión de la comunicación, caracterizada por la privatización de la experiencia comunicativa: desde los pequeños teatros o espectáculos, y las fiestas informales a las plataformas personales de comunicación como twitter, facebook, blogger y tanto otros aparecidos recientemente en la red. Nos hemos alejado cada vez más del espacio público, nos hemos aislado en la esfera privada y desde aquí, nos presentamos públicamente al mundo a través de nuestros ordenadores. Aunque, al final, este hecho se convierte en una experiencia narcisista que no ayuda realmente a encontrar nuestra identidad. Además, esta esfera comunicativa privatizada es la otra cara de la crisis de la dimensión de lo público tal como se había entendido en la modernidad.

El sociólogo británico Anthony Giddens también habla de esta novedad surgida desde que la persona dispone de un carácter único y posibilidades especiales, que no existía en la cultura pre-moderna. "En la Europa medieval el linaje, el género, el rango social y otros atributos decisivos para la identidad estaban relativamente fijados. A lo largo de los diversos estadios de la vida se producirían cambios; pero tales cambios estarían dirigidos por 
procesos institucionalizados y el papel del individuo en ellos era relativamente pasivo" (Giddens, 1995:98). Los sociólogos Berger y Luckmann, por su parte, también hablaron de que, en las sociedades tradicionales con unos programas institucionales simples, la identidad de cada persona era clara y permanente para todo el mundo. (Berger y Luckmann, 1988).

En Pinterest, la necesidad de recreación de la identidad se consigue a partir de la exhibición de aquello que idealizamos o que queremos que nos represente.

El concepto de organización de intereses no es nuevo. La mayoría de las personas, desde los inicios de la fotografía digital, han guardado las fotografías en carpetas dentro del ordenador, contenedor que mantiene cierta relación con las antiguas cajas de zapatos donde se guardaban las fotografías de forma desordenada en la era analógica.

Con Flikr los usuarios ya organizaban sus series de fotografías, que se pueden compartir con los demás usuarios una vez clasificadas por temas (tags). Así, la plataforma Flickr tiene una voluntad temática mayor que los álbumes fotográficos analógicos y en esta página las imágenes familiares comparten sitio con las imágenes de naturaleza, de vacaciones y de temas diversos, como demuestran los estudios de Nancy van House (Van House, 2004) y de Kris Cohen (Coen, 2005). El primer paso, abrir las fotografías que clasificamos a temas más dispares que el de la propia familia, ya estaba hecho. Las palabras clave más utilizadas en la historia de Flickr son, según fuentes de la misma página, palabras como boda, Nikon, naturaleza, familia, fiesta, Japón, playa, Canon, California... Así que el tópico "familia" está presente entre los temas más fotografiados, pero no se puede considerar la plataforma Flickr como un sustituto digital de los álbumes de familia, sino como un soporte donde estas fotografías familiares tienen cabida, pero también todas las demás.

Las aportaciones de la norteamericana Nancy van House son un gran referente a la hora de establecer les usos básicos de este tipo de fotografías. Van House, de la Universidad de California, ha estudiado los usos sociales de las cámaras fotográficas, así como de los dispositivos telefónicos móviles con cámara y las plataformas más populares de intercambio de fotografías entre usuarios. En sus investigaciones se analiza en detalle el porqué del hecho de disparar y compartir fotografías más que aquello que se muestra y cómo se muestra. En su estudio The Social Uses of Personal Photography, realizado el 2005, describe cuatro usos básicos de las imágenes personales:

1.- El memorístico, narrativo e identitario: las fotografías nos ayudan a construir narraciones de nuestras vidas y a formarnos una idea de identidad y colectividad.

2.- El de sustentar relaciones sociales: las fotografías refuerzan los vínculos entre generaciones y colectivos.

3.- El de la auto representación: la fotografía nos permite mostrarnos tal y como queremos ser vistos por los otros. Los autorretratos, las imágenes de la familia y de los amigos, de las posesiones y de las actividades que desarrollamos manifiestan nuestra manera de ser. 
4.- El de la auto-expresión: las fotografías reflejan el punto de vista del autor, y muestran su concepción estética y creativa.

Otro estudio sobre los usos de las fotografías en las redes sociales, en este caso centrado en la plataforma Facebook, es el del profesor Ben Zhao también de la Universidad de California en los Estados Unidos. Zhao estudió los perfiles de Facebook de 63 estudiantes universitarios, a partir de los cuales estableció tres tipos de voluntades:

1. Proyectar la imagen de uno mismo como deseable socialmente, a partir del gran número de fotografías de grupo en las fotografías del perfil

2. No parecer un nerd (idiota), sino manifestar una buena educación, a partir de la información que se da en el perfil sobre los estudios y la formación.

3. Demostrar concienciación social (thoughtfullness), a partir de las citas que se escriben.

Es decir que, 'Not onlywere they were not projecting pessimistic, apprehensive, unspontaneous or narrowly focused personas, as we have seen, but they were doing very little to claim academic identities either' ' (Zhao, 2008). Los resultados de esta investigación también demostraban que la identidad no era una característica únicamente individual, sino que es un producto que depende del entorno social y del contexto.

El primer uso de los apuntados por Van House también era compartido por los álbumes analógicos de fotografía, y en parte también el segundo. Pero el tercero y el cuarto son exclusivos de estas páginas digitales como la analizada Pinterest, dónde se comparten fotografías. Y el estudio de Zhao nos muestra la voluntad de presentar una identidad agradable para los demás.

Además, ahora, con Pinterest, no sólo se comparten fotografías de distinta temática sino todo aquello que encontramos interesante, a través de una plataforma de Internet cuya función, a la vez que contenedora, es exhibidora. No se trata de organizar sólo nuestros archivos, sino el mundo entero.

De esta manera, los usuarios se convierten en prosumers (Alvin Toffler acuñó el término en su obra "La tercera ola", a partir de la fusión de las palabras PROducer (productor) y conSUMER (consumidor), hecho que ya predecía la aparición de un nuevo tipo de consumidor activo) o emerecs (de "EMetteur-Etre-RECepteur", acuñado por Clotier en 2001).

Se trata de crear un banco de imágenes personal y propio. Corbis al revés: son los usuarios los que van conformando aquello que les gusta. La selección es democrática, ninguna institución ordena previamente la información a la que los usuarios tendrán acceso. 


\subsection{Organizar los intereses personales}

Pinterest es también un contenedor dónde el usuario archiva públicamente aquello que le interesa, pudiendo hacerlo en la página social, en lugar de en el propio ordenador de manera privada.

Cada vez la organización de aquello que nos gusta se hace menos dentro del propio ordenador individual, y más dentro de la red, en un espacio virtual llamado "nube". Este concepto empezó a finales del siglo XX, con la aparición de ordenadores sin disco duro pensados básicamente para la conexión a Internet. Esta nueva forma de organización está así siempre disponible. Aunque, lógicamente hay una pérdida de control. Antes de Pinterest ya existían marcadores sociales de favoritos (como del.icio.us, stumbleupon.com, Mister Wong o connotea.org). Estas páginas son un caso particular de etiquetaje social que permiten almacenar y catalogar las direcciones web, tal como lo haríamos con la opción "Favoritos" de nuestro navegador.

En Pinterest, la manera de organizar los datos se hace a través de etiquetas o tags que atorga directamente cada usuario. Los usuarios califican y clasifican así su propia información. "Con el tag, el webactor adquiere poder sobre el dato, e integra en él su inteligencia y pude compartirla con los demás, lo que hará que sus relaciones sean más dinámicas". (Pisani, 84)

A partir de esta catalogación personal, se llega a la folcsonomía: neologismo que deriva del término folk (popular) y taxonomía (administración del orden tal y como lo conciben los archiveros y los bibliotecarios). La folcsonomía es la clasificación realizada por los webactores, o usuarios empoderados, cuando etiquetan los objetos web y comparten estos tags. (Pisani, 84). Tradicionalmente, profesionales especializados calcificaban los objetos. Actualmente, cualquier usuario de Internet puede realizar su propia clasificación de los recursos presentes en la red mediante el uso de estos tags. De hecho, en Internet proliferan desde hace tiempo aplicaciones que permiten estas prácticas como YouTube o Flickr. Estas aplicaciones también permiten tener acceso a las direcciones web o marcadores, en lenguaje especializado, almacenados por otros usuarios con intereses similares a los nuestros y acceder a los marcadores identificados con una determinada etiqueta, independientemente del usuario que la haya introducido. Por tanto, los marcadores sociales facilitan, por un lado, el almacenaje y clasificación de nuestros marcadores y, del otro, la búsqueda de nuevos marcadores afines a nuestros intereses, clasificados por otros usuarios. A menudo las aplicaciones de marcadores sociales van más allá y ofrecen otras posibilidades como la creación de grupos o la sindicación de contenidos.

La folcsonomía es inclusiva, no se limita a categorías pre-establecidas. Es espontánea, se crea al momento. Sí que es cierto que no hay manera de evitar plurales y singulares para etiquetar una misma cosa, hecho que crea confusión, ni el uso de sinónimos, y en este sentido existe una falta de precisión. Pero los usuarios van aprendiendo unos de los otros y al final hay categorías que se van haciendo más populares. 
Se llega así a lo que Morville (2005) llamó findability, el diseño de metodologías para mejorar la clasificación de la información en la web, partiendo de la inteligencia colectiva de muchas personas al valorar y etiquetar la información.

La sabiduría de las multitudes, la mente enjambre (the hive mind) y la inteligencia colectiva están haciendo lo que hasta ahora sólo hacían los expertos catalogadores. Se trata del empoderamiento de los usuarios.

En cierto modo, hemos pasado de la era de las TIC (las tecnologías de la información y la comunicación) a la era de las TEP (las teorías del empoderamiento y participación), como las ha bautizado la socióloga Dolors Reig. Las TEP implican así no sólo el término de colaboración sino también de participación, ya que obtenemos algo a cambio de nuestra colaboración. No sólo se busca interactuar, sino ver que nuestras opiniones son tenidas en cuenta. En el caso de la plataforma que nos ocupa, Pinterest, son los propios usuarios quiénes crean ahora tendencias y proponen un catálogo de aquello que consideran interesante en la red.

\subsection{Conocer gente como tú}

También está claro que las folcsonomias propician el sentimiento de comunidad. Las personas que etiquetan sus imágenes con los mismos nombres acaban formando parte de una cierta "tribu virtual". La página actúa así como los "virtual large groups" de los que habla Haim Weinberg (Weinerg, 1988), dónde los individuos se apoyan y crean vínculos comunitarios entre sí. Weinberg describió concretamente las características de los chats, pero muchas de éstas son extraplorables también a Pinterest, ya que existe igualmente la sensación de formar parte de un grupo, de ser una comunidad. La propia página se anuncia así: "El objetivo de Pinterest es conectar a todo el mundo a través de las 'cosas' que encuentran interesantes. Un buen libro, un juguete o receta de cocina... Puede revelar un vínculo común entre dos personas. Con millones de nuevas ideas agregadas cada semana, Pinterest conectara a las personas de todo el mundo sobre la base de sus gustos e intereses compartidos".

Así, a diferencia de lo que sucedía, por ejemplo, en otras páginas como Photoblog, dónde las personas que aparecían en las fotografías eran básicamente el propio autor, sus amigos y su pareja (Visa, Merola, 2012); en Pinterest no sólo se organizan y se exhiben las propios intereses a personas ya conocidas, sino que hay voluntad de conocer a otras personas, de ampliar círculos a través de estos intereses, para conocer personas afines.

\section{CONCLUSIONES}

Los nuevos usos de las fotografías en las redes sociales muestran como, más allá de la representación, las imágenes (personales o ajenas) sirven también actualmente para la auto-representación y para la comunicación entre usuarios. En Pinterest, todo aquello que interesa, representado con imágenes, se exhibe al resto de usuarios, formando así una especie de escaparate con todo aquello a lo que uno quiere ser asociado. 
Los usuarios de Pinterest ya no se presentan públicamente como aquello que realmente son, sino que muestran a los demás una parte idealizada de sí mismos, representada tanto por aquellas imágenes propias con las que se sienten cómodos (hecho que ya ocurría y sigue ocurriendo en otras redes sociales anteriores) como por aquellos objetos con los que quieren que los identifiquen. La privatización de la experiencia comunicativa propiciada por las redes sociales permite así la autorepresentación a la carta.

Además, de la autorepresentación a través de imágenes, Pinterest permite la comunicación entre usuarios con gustos similares, ya que cada interés personal puede volverse a distribuir al ser compartido por más usuarios.

Es también una red que permite la clasificación y catalogación hecha por los propios usuarios, ya que el etiquetaje del contenido no viene dado, sino que es el mismo usuario quien lo propone, creando así el sentimiento de comunidad. Las personas que etiquetan sus imágenes con los mismos nombres acaban formando parte de una misma "tribu virtual", con intereses compartidos. La necesidad contemporánea de sentirnos representados y etiquetados, de poner nombre e imágenes a nuestro alrededor, se beneficia así de la aparición de redes sociales como Pinterest, que permiten crear la ilusión de estar coleccionando el mundo. Las nuevas formas de etiquetado, más democráticas al ser propuestas por los usuarios y no venir predefinidas permiten que la inteligencia colectiva sea la que marque las tendencias de que es aquello que más interesa a los usuarios en cada momento.

Los usuarios de Pinterest no se limitan pues a producir contenido o a a consumirlo, sino que se pueden apropiar virtualmente de él (coleccionándolo), utilizarlo como representación propia, y distribuirlo de nuevo para darse a conocer by propiciar el conocimiento de gente con intereses similares.

\section{REFERENCIAS}

Bauman, Z. (2005). Modernidad y ambivalencia. Anthropos. Barcelona

Berger, P.; Luckmann, T. (1988) La construcció social de la realitat. Ed. Herder. Barcelona.

Capdevila, J. (2010). Construcció de les identitats (g)locals i noves tecnologies de la informació i de la comunicació. Lleida: Ajuntament de Lleida.

Cloutier, J. (2001). Petit traité de communication. Emerec à l'heure des technologies numériques.

Cohen, K. (2005). “What does the photoblog want?” Media, Culture, Society. Vol.27.

Codina, L. (2009). “¿Web 2.0, Web 3.0 o Web Semántica?” El impacto en los sistemas de información de la Web. I Congreso Internacional de Ciberperiodismo y Web 2.0. Bilbao: Universidad del País Vasco (978-84-9860-058-2) 
Domingo, J. (1996). "Fotografía e Internet: la apuesta de Gates". Cuadernos de información, $\mathrm{n}^{\mathrm{o}} 11$.

Giddens, A. (1995) Modernidad e identidad del yo. Ediciones Península. Barcelona.

Gil Posa, M. (2010). “Tag me. Identidad: (re)creación y (re)presentación en las tecnologías digitales". En Espéculo. Revista de estudios literarios. Universidad Complutense de Madrid.

Lipovetsky, G.; Serroy, J. (2007) La pantalla global. Barcelona: Anagrama. Colección argumentos.

Morville, P. (2005) Ambient Findability. Sebastopol: O’Reilly Media.

Mosquera, G. (ed). (2011). Interfaces. Retrato y comunicación. PhotoEspaña 2011. Madrid. La Fábrica Editorial.

Pisani, F.; Piotet, D. (2008) La alquimia de las multitudes. Madrid: Paidós Comunicación.

Reig, D. El Caparazón. http://www.dreig.eu/caparazon/

Shcneider, S.; Weinberg, H. (2003). The large group re-visited. Jessica Kingsley Publishers.

Van House, N. A.; Davis, M.; Takhteyev, Y.; Ames,M.; Finn, M. (2004) From 'What?' to 'Why?': The Social Uses of Personal Photos.

Vattimo, G. (2003). En torno a la posmodernidad. Barcelona: Anthropos Editorial.

Visa, M.; Soto, J. (2012) “El uso del photoblog como narración, juego y construcción de la propia identidad". Congreso Internacional: RELATO digital STORYTELLING. Valencia: Universidad de Valencia.

Visa, M. (2011). “La re-creación de la identidad a través de la fotografía en las imágenes de perfil de la red social Facebook". Congreso Internacional Latina de Comunicación Social. Universidad de La Laguna.

Zhao, S.; Sherri Grasmuck, J. M. (2008) “Identity construction on Facebook: Digital empowerment in anchored relationships". En Computers in Human Behavior, 24. 18161836. Department of Sociology, Temple University, United States.

Http://www.huffingtonpost.com/brian-honigman/100-fascinating-socialme_b_2185281.html 


\section{Mariona Visa Barbosa}

Licenciada en Comunicación Audiovisual por la Universitat Pompeu Fabra de Barcelona en 2001. Doctora en Comunicación Social en 2012 con la tesis titulada "L'álbum fotogràfic familiar: evolució sociológica i narrativa". Actualmente trabaja como profesora investigadora en la Universitat de Lleida, en el Grado de Periodismo y Comunicación Audiovisual, investigando temas de fotografía, redes sociales y narrativa, como los nuevos usos de las fotografías familiares en las redes sociales. 